\title{
Ailanthus Altissima (Mill.) and Varroa Destructor (Anderson \& Trueman) - Two Alien and Invasive Species with Impact on the Environment and on the "Hive System"
}

\author{
T Gardi ${ }^{1 *}$, M Micheli $^{1}$ and M Petrarchini ${ }^{2}$ \\ ${ }^{1}$ Department of Agricultural, Food and Environmental Sciences, University of Perugia - Borgo XX Giugno, Italy \\ ${ }^{2}$ Beekeeping Expert, Beekeeper Registered in the National Register of Italian Bee Breeder, Italy
}

*Corresponding author: T Gardi, Department of Agricultural, Food and Environmental

Sciences, University of Perugia, Borgo XX Giugno, 74, 06121 Perugia (PG), Italy.

Received Date: January 21, 2020

Published Date: February 12, 2020

\section{Abstract}

In past times, very often, human curiosity and the attraction towards "exotic" animal and plant species aimed at enriching public and private gardens, led to the introduction of alien species, as in the case of Ailanthus altissima (Mill.), species proved invasive, with serious consequences for the environment, as it is able to colonize entire territories in a short time at the expense of the native flora that characterized them and which is increasingly replacing faster. In the same way it happened with regard to the "Hive System" with the introduction in Europe and in Italy of the mite Varroa destructor (Anderson \& Trueman), endemic parasite of the Cerea Bee, which once "reached" the colonies of Apis mellifera, through the uncontrolled import of queen bees and swarms, it has spread to an epidemic character and is still the undisputed scourge of Italian beekeeping, with serious repercussions on agricultural production and safeguarding the biodiversity of the different ecosystems of the Italian peninsula.

Ailanthus Altissima (Mill.) - The Tree of Paradise that is Creating the Hell of Agro-Ecosystems

Ailanthus altissima (Mill.), Is a genus of plants of the Simaroubaceae family, which includes seven species of trees originating in the tropical areas of Asia and Australia, which can reach heights just over $25 \mathrm{~m}$. The common name is ailanthus or tree of paradise.

Introduced in Italy also for ornamental purposes, it has proved over time to be a highly infesting, very aggressive plant, with a very rapid proliferation, whose roots extend in width up to thirty meters from the trunk, giving rise to colonies of new daughter plants both for root suckers than via gamic (from seed). The bad smell emanating from its leaves is known.

The stem, of very little commercial value, as it is soft and not durable wood, is generally erect and very branched with a lighter brown-gray bark on the young branches. The leaves are composed, pinnate, spiraled or opposite, and without stipules. The flowers, gathered in spike or panicle inflorescences, are generally unisexual.
The most widespread species in Italy, Ailanthus altissima (Mill.), Is dioecious, i.e. each tree of this species hosts only male or female only flowers. It produces winged dried indecent fruits (samare). It was introduced in Italy for an attempt to breed the moth Philosamia cynthia originating in the Far East for the production of silk, it is now found in the woods, on the ripe, on the greti, on arid, stony and unstable soils, along the roads and close to of the walls of buildings and in the splits of reinforced concrete pavements. Its spread goes from the plains to the mountains, becoming a very aggressive weed. It slowly replaces the existing native vegetation, forming colonies. It is also found more and more often in cities, where it is used, unexpectedly and thoughtlessly, as a quick remedy against the sun's rays; the plant is in fact known also for the extreme rapidity of growth in height. Its weed characteristics, however, should suggest careful control of its propagation, which has long been ignored for too long. In fact, the ailanthus is spreading in an increasingly worrying way at the expense of the pre-existing indigenous vegetation, in Umbria we find it, in fact, also on the summit slopes of Subasio Mount, 
along the left side of the road that from the Eremo delle Carceri leads to Collepino - Spello (PG). The species is spreading so rapidly that today it is difficult to try to eliminate it as the cutting of adult plants leads to the issue of numerous shoots of radical origin even at considerable distances from the place where the adult is located. The only system to be able to contain and eliminate it from an area, respecting the environment, consists in cutting the trunks of the existing plants at about 1.5 meters in height and letting recesses form on the trunk; these must be eliminated by "crushing", in the middle of summer, repeatedly and for several consecutive years, so as to obtain complete drying of the stump due to the weakening and rotting of the wood with a soft and centrally suber consistency. Clearly, this type of intervention can only be proposed in private properties and with still a low number of individuals settled, as it requires assiduity and availability of manpower. In all other cases, even if it is not environmentally possible, the only remedy is the use of synthetic systemic herbicides.

American studies [1] have shown that excellent results can be obtained by resorting to the use of 2 specific active synthetic ingredients: Picloram and Triclopir. These molecules are contained, respectively, in the commercial products available in Italy under the name: TORDON $22 \mathrm{~K}^{\circledR}$, a systemic herbicide with leaf and radical absorption, persistent in the soil and with a broad spectrum of action. Particularly used for weeding uncultivated areas, roads, industrial areas, etc.; in the reclamation of pastures, against ferns, romici, etc.; in maintaining the cleanliness and integrity of the nets and in any case of the fences. The product is highly phytotoxic for poplar, vines, orchards, arboreal and herbaceous crops in general. Absolutely to avoid treatments on windy days and pay attention to any neighboring crops avoiding them being affected. The second commercial product is GARLON $\mathrm{EV}^{\circledR}$ ) whose active molecule, Triclopir, puts it into use as a systemic, non-residual herbicide. The synergy of the two active ingredients enhances the action on plants that are difficult to control, making it more effective than the well-known Glyphosate (Roundup ${ }^{\circledR}$ ), banned in some EU countries and beyond (Malta, New Zealand, the Netherlands, Portugal, Spain, Scotland, Slovenia, Sri Lanka, Sweden, Switzerland, the United Kingdom and Vietnam), for precautionary reasons as a substance believed to be at risk of procuring cancer and highly polluting for agro-ecosystems. The Triclopir molecule is quickly absorbed by plants and translocated both downwards and upwards. The product is most effective in the active growth phase. Compared to Picloram, Triclopir is rapidly degraded by soil microorganisms (2 hours). It is not volatile and can therefore be used near green areas to be protected without danger of drift damage. Its effect manifests itself after a few days. These herbicides given in succession and repeatedly during the summer (from May to September) must be applied to the green leaves and stems, including shoots and suckers, until these are completely wet, but not to the point of outflow of the mixture. The first lasting results are obtained six weeks after the treatment. Unfortunately, against this alien and invasive species, too long ignored by public institutions and private citizens, this turns out to be the only effective control method, as it is able to kill young trees born from seed and able to prevent regrowth from root suckers, as once moved to the root system, it kills the roots. In the case of isolated specimens, the fight can be conducted by directly injections with the aforementioned active ingredient, directly at the base of the trunk, thus avoiding that the molecule can reach different and neighboring plant species.

The only positive aspect attributable to ailanthus is that it is a nectariferous species from which, in certain vintages, good monoflora honey can also be obtained. In fact, contrary to the unpleasant smell emanating from the different parts of the plant (leaves and stem), given the spread of the species and its flowering that occurs in June, ailanthus honey tends to hide the flavor of many other types of honey, like acacia and linden, while adding a very pleasant note to many kinds of wildflower honey. Ailanthus honey looks like a thick product with an amber color, which tends to crystallize quickly within a few months. The aroma of this honey is generally associated with that of fresh mushrooms, with a consistent fruit note. The flavor, on the other hand, is considered as intense and enveloping and reminiscent of Muscat, managing to be easily combined with sweet dishes, fruit salads or fruit ice cream, obtaining a delicious and refreshing food for the summer.

Ailanthus honey also has the ability to harmonize and bind very different flavors: it should also be tried with aged cheeses; Furthermore, it seems that this honey also has antiseptic properties: according to traditional Chinese medicine, ailanthus and its honey can have positive effects against infections and dysentery. In reality, the leaves of the plant and the plant itself have no healing properties, they can actually be harmful to the human organism. However, the antiseptic properties of honey are definitely more plausible. It appears to be a soothing anti-cough: According to some "popular" legends it is claimed that ailanthus honey can be a good ally for fighting respiratory problems. Excellent sweetener: thanks to its intense "fruit flavor", ailanthus honey is an excellent sweetener for herbal teas and more.

Varroa destructor (Anderson \& Trueman) - The Alien and Invasive Mite of the "Hive System"

Among the various pathologies affecting honeybee colonies, Varroa destructor (Anderson \& Trueman), is today the most dangerous parasite because if left unchecked it can lead to the collapse of colonies over the course of one or two bee seasons. Four species associated with the Apis cerana (Fabr.) Belong to the genus Varroa: Varroa jacobsoni Oudemans, Varroa underwoodi Delfinado \& Aggrawaal, Varroa rindereri de Guzman \& Delfinado, Varroa destructor Anderson \& Trueman. The latter only recently in 2000, thanks to Anderson \& Trueman it was possible to distinguish it from Varroa jacobsoni; discovered, however, in 1904 by Oudemans, on the island of Java and spread exclusively in Indonesia on Apis cerana and others, but it does not reproduce on A. mellifera and has little economic importance. Hence, most of the works published in the past on Varroa jacobsoni actually refer to Varroa destructor [2]. 
Originally, Varroa destructor, parasitized the Apis cerana to which it does not cause particular damage, but starting from the 1940 s to increase bee production, European bees were introduced to South-East Asia; from that moment the parasite was also found on A. mellifera. Subsequently, it was reported in Russia and spread, in almost all the countries of southern and south-eastern Asia and subsequently in almost all the countries of the world (Figures 1\&2) [2].

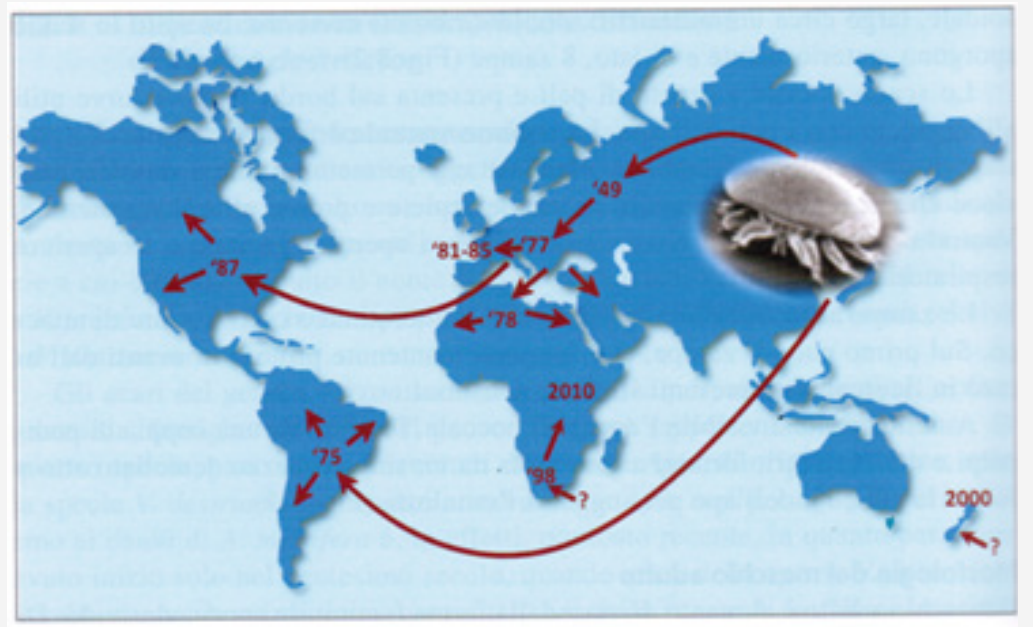

Figure 1: Diffusion of the Varroa destructor mite from the eastern bee to the honeybee [4].

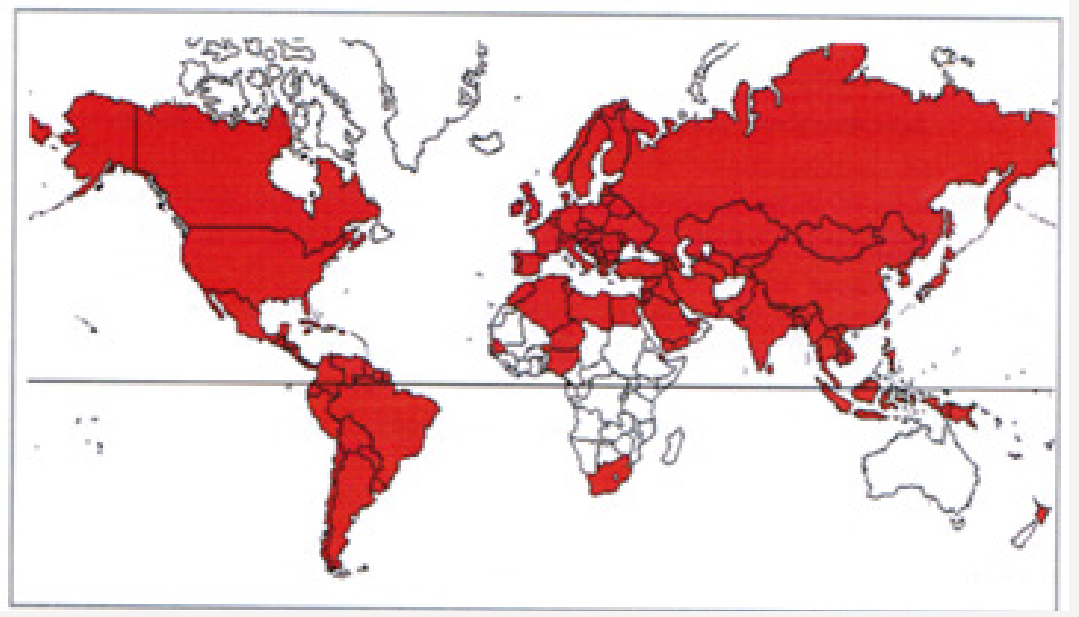

Figure 2: Distribution of the varroa mite in the world to 2010 (areas in red) [4].

As can be seen from Figure 2, V. destructor, it is widespread all over the world with the exception of Australia, thanks to strict import control systems even though experts predict that it will enter it soon because in recent years it has spread to countries neighbors. In Europe it is present everywhere, with the exception of some Scottish and Norwegian islands. In Italy, the first report of the mite occurred in 1981 in Friuli Venezia Giulia and in the following years it became ubiquitous throughout Italy, Europe and the United States of America [2].

There are 5 or 6 subspecies of V. destructor, of which the two most widespread and identified haplotypes are: the "Korean" one, the most aggressive and widespread in Europe, the Middle East, Africa, Asia and North America; while the latter, or "Japanese", is less aggressive and is widespread in Japan, Thailand and the Americas [2,3]. Morfologia e anatomia di V. destructor (A. \& T.).

The mite has a pungent-sucking mouthparts and acts as an ectoparasite for the duration of life, living both at the expense of the brood and at the expense of adults. It is characterized by an accentuated sexual dimorphism, the various forms present are described below: female, male and youthful.

The female of varroa stands out quite easily with the naked eye being its relatively large dimensions (1.1-1.7 x 1.5-1.99 mm) which differ according to the geographical areas. It is reddish brown in color, the body is flattened in the dorsal-ventral direction and has an ellipsoidal dorsal shield with four pairs of legs. The shield is covered with hair and on the edge, it has curved bristles 
that facilitate attachment with bee hair. Ventrally, the anus, genital opening and respiratory openings can be seen (Figure 3) [2,4,5].

The articulated legs end with attachment structures and when the mite is in search, those of the first pair are kept forward because the sensory structures are present in these. Anteriorly, the mouthparts can be seen, designed to perforate the bee membrane and the sucking of the hemolymph; the females are the only ones to carry out the direct parasite-removing action (subtractive action) on bees after having torn the integument with tiny toothed blades (mechanical-traumatic action) [4,5].

The adult male of $V$. destructor (Figure 4), very different from the female form, has a spherical shape, is whitish in color and smaller in size, about $0.8 \mathrm{~mm}$ in diameter. It has a soft and slightly keratinized body (confused with the female juvenile stage), with a convex-shaped dorsal shield provided with numerous hairs and showy sculptures. The 4 pairs of legs are facing forward, unlike the females. They die within a few days of birth (generally to the flickering of bees), they live entirely inside the brood cell where they are neither able to feed nor carry out the parasitic action as their mouth parts are transformed into organs for the transfer of spermatophores, containing spermatozoa, to fertilize females during mating $[4,5]$.

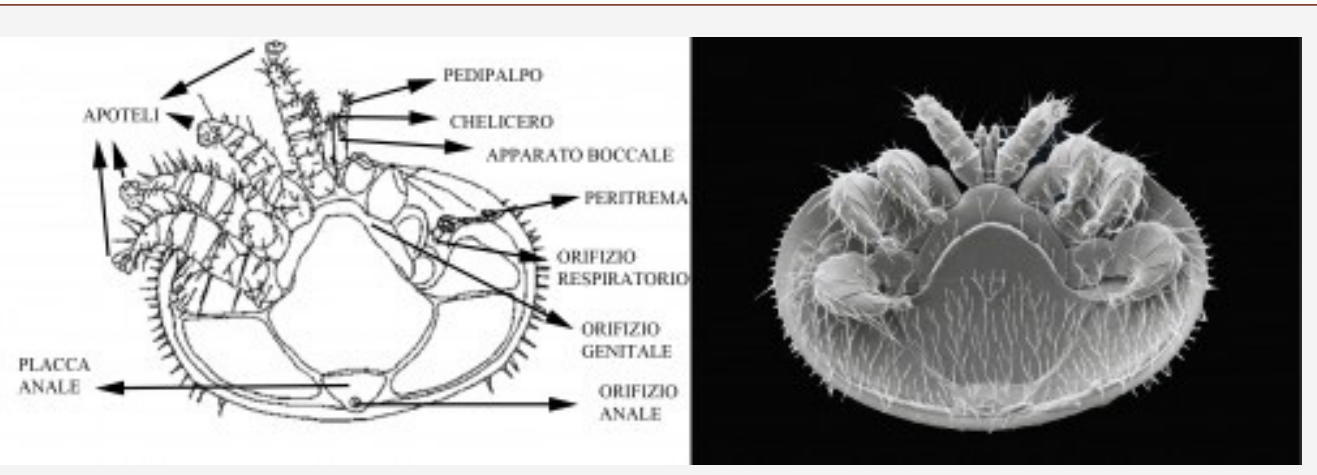

Figure 3: Ventral view of female of Varroa destructor [5].
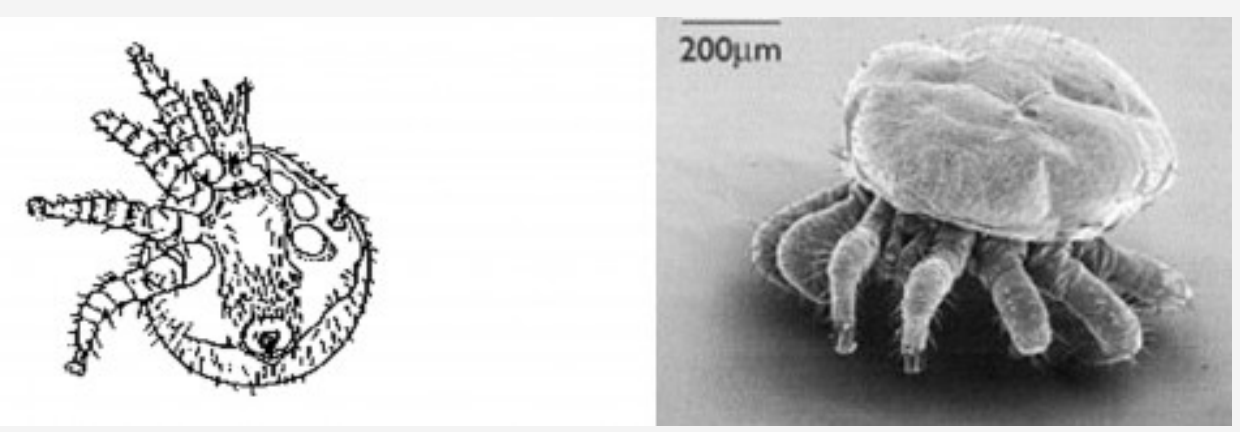

Figure 4: Varroa destructor male [5].

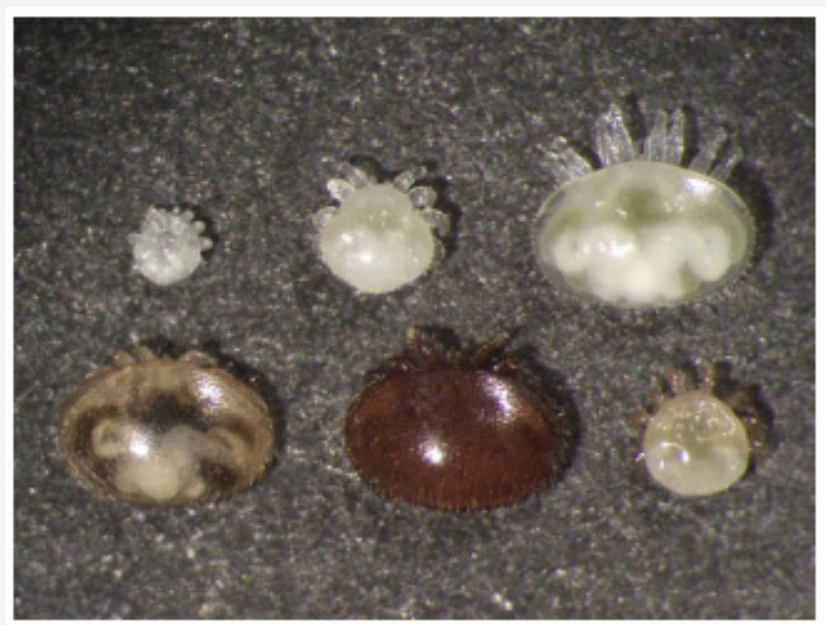

Figure 5: Stages and life forms of varroa: (A) protonymph; (B) deuteronymph; (C) deutocrisalide; (D) young adult female (E) founding varroa; (F) adult male (Rosenkranz et al., 2010, modified). 
Juvenile forms are formed from eggs: oval, whitish and about half a millimeter long, not easily visible to the naked eye. After 24 hours, a hexapod larva develops inside the egg; from this, after another 24 hours, a proton nymph leaks out of the egg. The male and female proton nymphs are similar to each other: rounded $(0.7 \mathrm{~mm})$, white in color, they have 4 pairs of legs stretched forward and poor mobility. The protonymph stage lasts 5 days in the female and 3 days in the male; after a further metamorphosis, deutonymph develops which lasts 1-2 days for both sexes. In these, sexual dimorphism begins to manifest (Figure 5): the females are larger and elliptical in size than the males. From this stage one passes in an immobile form, deuterocrisalide, and then the adult appears. The female of Varroa, in fact, acquires a brown color that tends to darken after the first 24 hours. Adult males, very similar to protonymphs, are distinguished from these by a more angular and smaller body $[4,5]$.
From egg laying to adult development, 8-9 days pass for females and 6-7 days for males; in these phases there is a significant mortality, especially for deutonymphs: on average only 1.4 females reach adulthood in a worker cell, against 2.2 in a drone cell [4].

In Figure 6, the development of the bee is reported, from prepupa to nascent bee, with the related forms of fertile varroe. From a study carried out on VSH (Varroa sensitive hygiene or specific hygiene for varroa), i.e. on the hygienic pressure that bees are able to perform on the population of varroe in the hive, it became known that this character, has the effect of percentage increase in varroe that do not reproduce or that reproduce too late, called infertile varroe. Through the Harbo test (by John Harbo), which evaluates the presence of varroe that do not reproduce, it is possible to select the colonies with the VSH character.

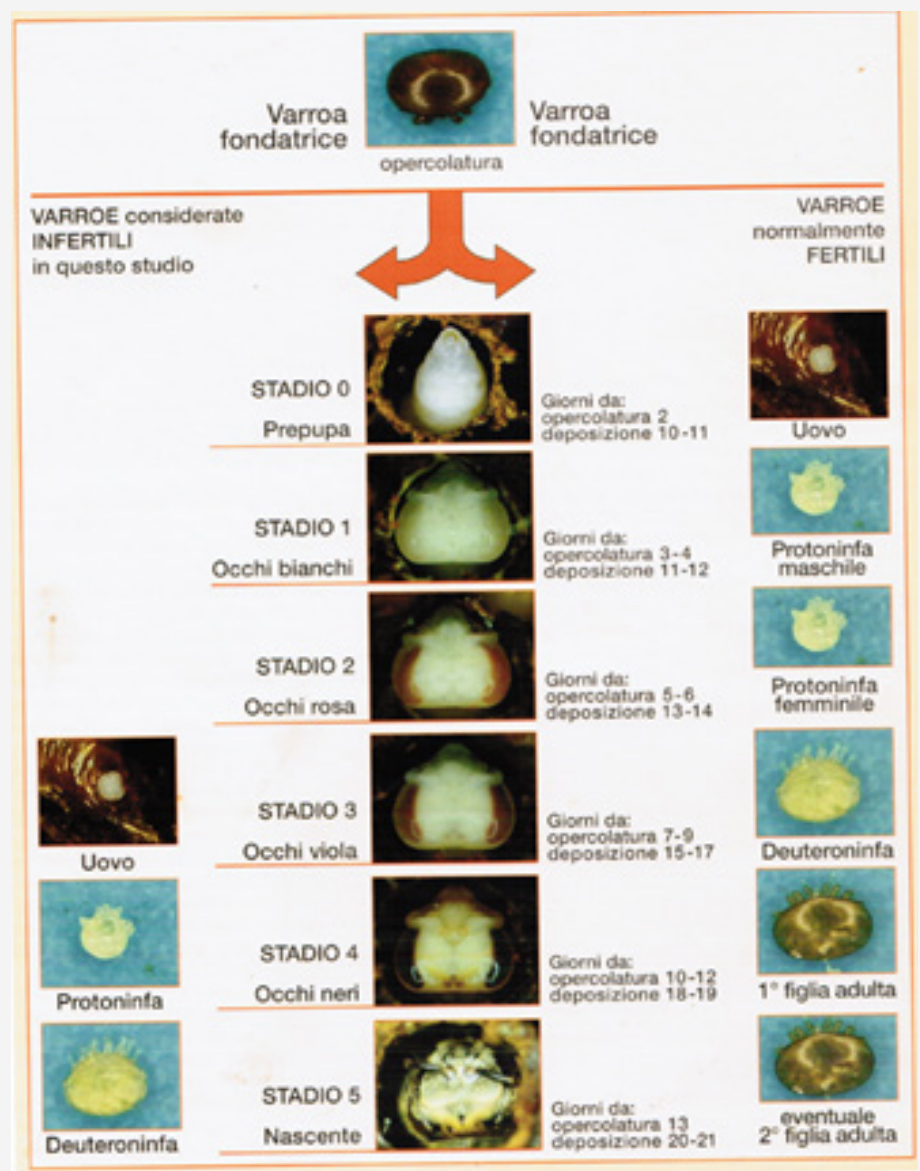

Figure 6: Stages of development of bees and varroe with related days from the peeling and egg laying [6].

The percentage variation between fertile and infertile varroe, through analysis of the reproductive cycle and related statistics, was quantified as 30 ; this value indicates the minimum number of cells infested by a single founding varroa that must be uncapped, analyzed and counted for the test to be valid [6].

\section{Varroa Destructor Biological Cycle}

Being a parasite, the Varroa destructor cycle, is synchronized with the bee cycle. It consists of a reproductive phase which takes place exclusively inside the operated brood and a for ethic phase on adult bees (Figure 7). In the laboratory it has been shown that a varroa can perform up to 7 reproductive cycles, but most varroe lays only once, few are able to carry out two or three cycles (21-14\%). Varroe prefer kelp cells because the duration of the metamorphosis of the worker bees is 12 days, while it is 15 days for the drones; a longer time allows the birth and fertilization of a greater number of females of the parasite. It has been seen, however, that they do not develop on the real cells, perhaps due to the composition of 
the royal jelly, where the octaonic acid, repellent for the mite, is present. The varroe are blind and in the hive, they manage to orient themselves and perform all their functions through semi-chemical interactions, i.e. the perception of the smells produced by the larvae and bees $[2,4,5]$.

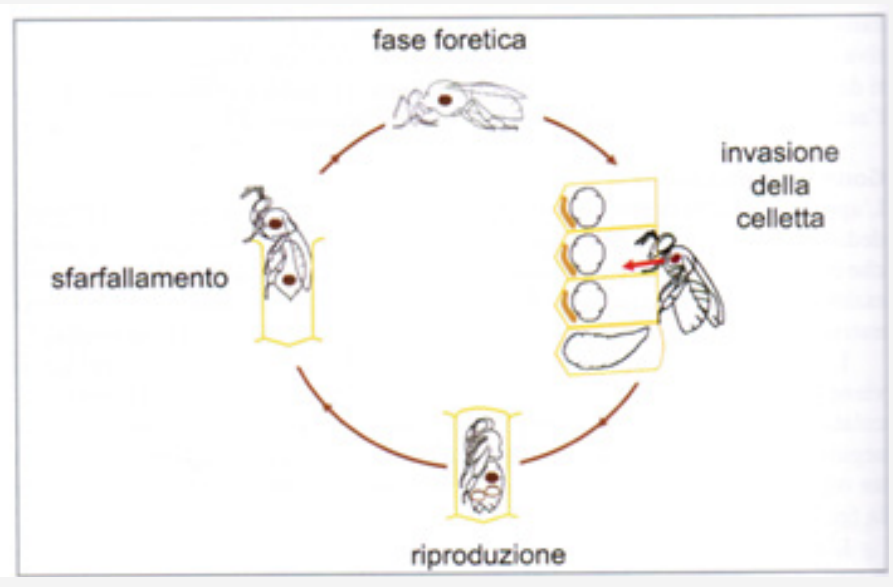

Figure 7: The biological cycle of the varroa mite, includes: foretic phases on adult bees and reproductive phases inside the bee's cells [4].

\section{The Reproductive Phase}

Adult females penetrate inside the cells containing a bee larva, about 15-20 hours before they are operculated (40-50 hours, for kelp larvae) and position themselves between the larva and the cell wall. After peeling, when the bee larva begins to feed on royal jelly, the mother varroa, perforating the cuticle, begins to feed on its hemolymph. After about 36 hours, the bee larva begins to weave the cocoon in which it will perform the metamorphosis. When the cocoon is finished, and the bee is in the preninfal phase, the founding varroa first chooses a place to collect its feces: faecal accumulation site (AF) that appears as a small white spot usually located in the back of the cell wall.

After two and a half days (60 hours) from the operculation, the mother varroa will lay its first egg in the front part of the cell, up to a maximum of 6 every 30 hours per reproductive cycle. From the first egg (haploid) the only male is born, while from the subsequent eggs (diploid) only females will be born, in order to allow the male to immediately mate with the first mature female and, subsequently, with the other sister females. The fertilized females, after 5 days, are already able to start a new reproductive cycle; if the male dies before mating, they will remain sterile. The feeding of the varroe always takes place at the level of the abdomen of the bee pupa so as not to compromise its survival, because if the bee's death occurs, consequently, the parasites would also be prevented from exiting the cell $[4,5]$.

\section{Foretic Phase of the Varroa destructor Mite}

When the bee flickers, the offspring of the mother varroa is found inside the cell (Figure 8). Thus, we pass to the foretic phase when the varroe adult and fertilized daughters leave the cell trying to get on adult bees. Inside the cell the males remain and will die, the female varroe at the preimaginal stages, or the adults who do not have the cuticle completely sclerified, because they cannot survive outside of it and do not have a mouthparts capable of piercing the bee integument [4].

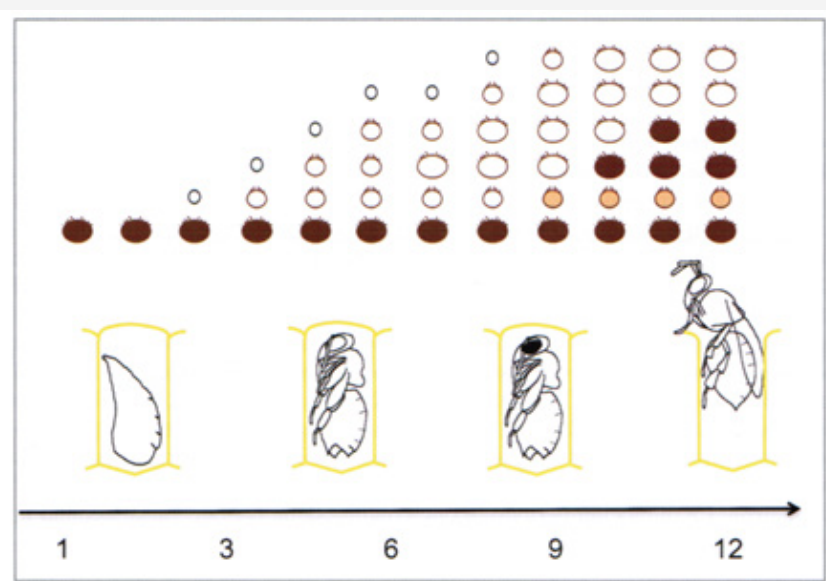

Figure 8: Varroa development sequence. The arrow represents time in days, you can see the stages of development of the bee and above, the stages of development of the varroa mite [4]. 
Those that come out do not go autonomously towards the cell but reach it transported by an adult bee and are abandoned only a very short distance from the cell containing a larva; whose attraction to the brood occurs, as mentioned, by chemical signals. Furthermore, varroa is able to distinguish the age of adult bees, thus preferring sucker bees for transport, because they are the bees that take care of the brood $[2,4,5]$.

The duration of the foretic phase is quite variable, it depends on the amount of brood, the strength of the colony and other factors. During some experiments, it has been observed that the time necessary for half of the varroe introduced into a hive to invade a cell is between 2 and 8 days, the time for which the varroa passes between the ventral laminae of the segments of the abdomen. When the colonies are brood-free, the varroe overwinter on the workers' bodies, and they can remain there for up to 6 months, waiting for the brood to reappear $[4,5]$.

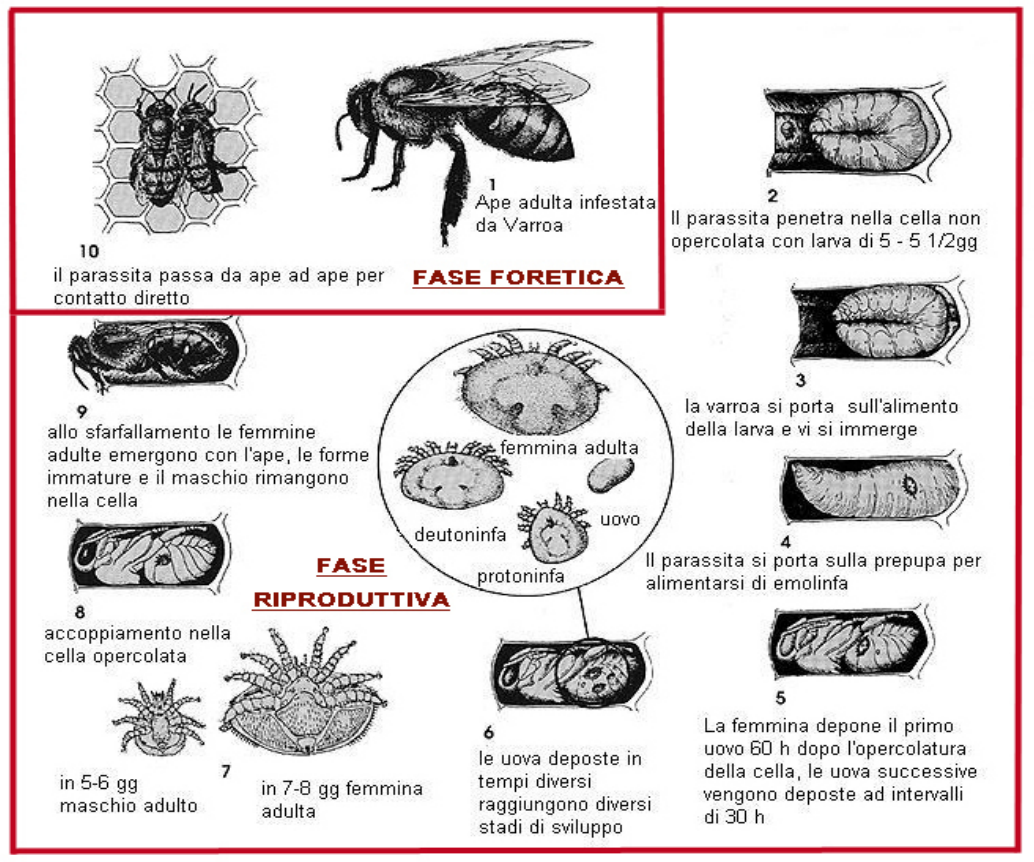

Figure 9: Biological cycle of V. destructor, foretic phase and reproductive phase.

Figure 9 summarizes the Varroa destructor cycle, in the various phases it comprises.

\section{Damage Caused by V. destructor (Anderson \& Trueman) to the "Hive System"}

Following the dynamic of the development cycle of the varroa, in the absence of acaricidal treatments, the population of the parasite inevitably tends to increase from the spring recovery to the autumn. It is assumed that the population in the presence of brood can double in number every month, so a reasonably low infestation in spring can also cause the presence of thousands of individuals in autumn. The use of suitable acaricidal treatments allows the infestation to stabilize on acceptable values, such as to determine a "coexistence" or a certain balance with bees. The effects of parasitosis can be distinguished in: direct damage affecting the individual bee and, indirect damage, i.e. secondary infections and diseases that are associated with varroa and that can lead to the collapse of the colony [4].

\section{Direct Damage to the Honeybee Colony}

The direct damage that varroa mite causes to bees, are mainly developmental alterations as well as effects of loss of orientation and weakening.

The main effect that has been found concerns weight loss that can exceed $10 \%$, in the case of bees infested by a single parasite; and it has been shown that this loss does not only concern a reduction of the hemolymph stolen from the bee, but also the loss of water. In addition, parasitized bees are born with a reduction in the levels of protein concentration in the head and abdomen (20\%). For these conditions, the life expectancy of bees is reduced by $50 \%$ [4]. As a consequence of this, there may be reductions in the population, evident flight difficulties, problems with the queen and also the presence of tracheal mites. In the brood, an irregularity of this can be observed above all, symptoms similar to European plague, American plague or sack brood and larvae out of place in the cell or dark-colored [2]. 


\section{Indirect Damage on Adult Bees and on Broods}

Direct damage is not insignificant but is of secondary importance with respect to the transmission of viruses, in fact, the main cause of mortality of the infested colonies is the viral infection that occurs.

Twenty viruses have been identified in the bee [7], the most harmful being the deformed wing virus (DWV) (Figure 10) and the acute paralysis virus (Acute Paralysis Virus, APV). Varroa is able to transmit and transfer viruses between bees and this assumes that the virus is able to replicate within the parasite, a capacity that is still uncertain, except for the deformed wing virus [4]. In $50-80 \%$ of cases, the mite transfers the virus from an infected pupa to a healthy one, therefore, as the infestation increases, the risk of spreading the virus itself increases [2]. Therefore, these transmissions must be avoided or at least reduced to keep the varroe in low numbers, generally treating the removal of the honey bees in late summer, avoiding dangerous delays in the treatments because this entails the birth of winter bees infected with viruses, and there is a risk that the colony succumbs during the winter.
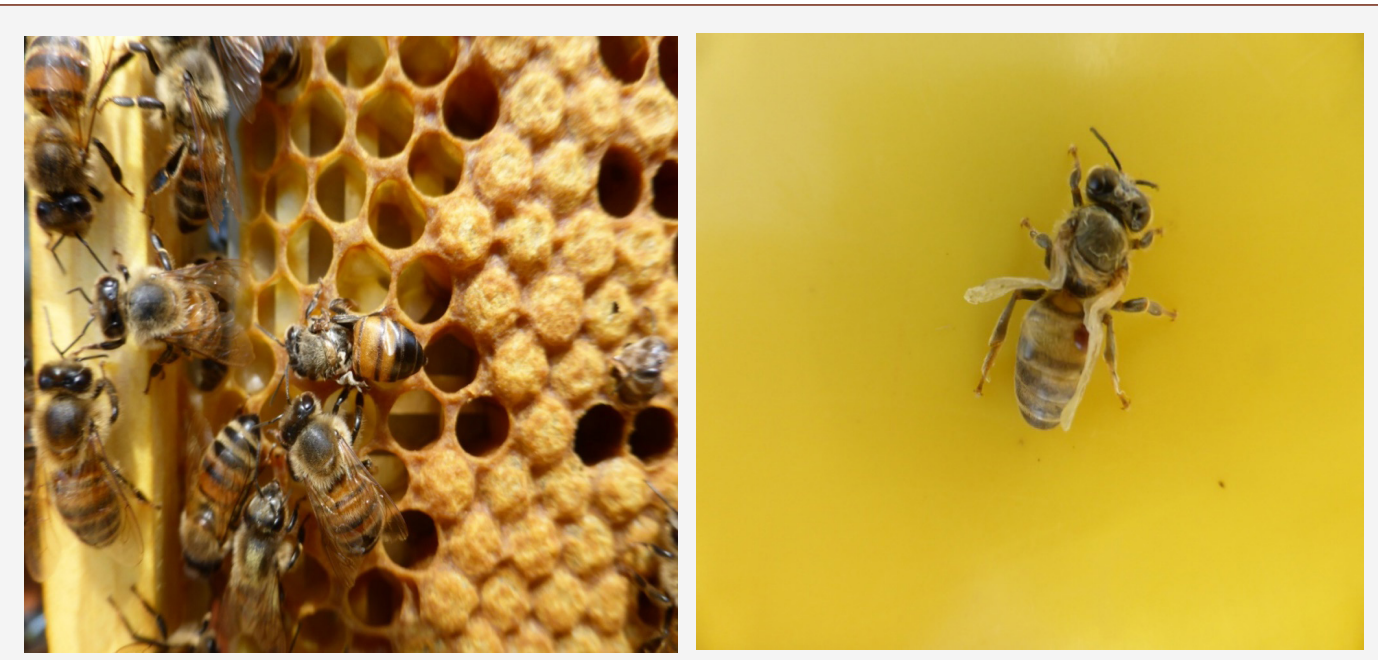

Figure 10: Worker bee with misshapen wings (left); young worker bee with misshapen wings and with an adult of varroa in the upper part of the abdomen (right) [15].

According to a recent study conducted by Schroeder in 2015 on the deformed wing virus, it has been observed that, in England, some apiaries have an avirulent strain of DWV (called type b), and that they are also immune to the more virulent strain (type a ) which instead causes the colonies to collapse; the presence of a third strain (type c) has also been observed, the characteristics of which are not yet certain. This new interaction could be exploited to minimize the problems caused by this virus (Schroeder, 2015). Finally, the acute paralysis virus, in severely infested colonies, can also cause a considerable mortality of uncapped brood as well as shortening the life of adult bees which, following this virosis, present tremors and weakening. To date, unfortunately, beekeepers do not have a pest eradicating care system; so much so that the methods of struggle are based on the application of biotechnics (confinement of the queen, use of heat, etc ...) that allow interventions with low chemical impact on the hive system [8-10], or through the use of chemical molecules that do not always guarantee the health of bees and consumers [11-22].

\section{Acknowledgement}

None.

\section{Conflict of Interest}

No conflict of interest.

\section{References}

1. Patrick L Burch, Shepard M Zedaker (2003) Removing the invasive tree ailanthus altissima and restoring natural cover. Journal of Arboriculture 29(1): 18-24.

2. Contessi A (2014) The bees. Biology, breeding, products, $7^{\text {th }}$ reprint of the $3^{\text {rd }}$ edition 2014.

3. Anderson DL, Trueman JWH (2000) Varroa jacobsoni (Acari: Varroidae) is more than one species. Exp Appl Acarol 24(3): 165-189.

4. Carpana E, Lodesani M (2014) Pathology and adversity of the hive CRA-API, Council for research and experimentation in agriculture. Ed Springer Verlag Italy (ML).

5. Giacomelli A, Pietropaoli M, Pizzariello M, Capomolla I, Formato G (2013) Varroa destructor anatomy and biology pills Experimental Zooprophylactic Institute of the Lazio and Tuscany Regions, topics 1: 66-70.

6. Costa C, Bigio G, Piemontesi A (2015) VSH project. Varroa sensitive hygiene, Aspromiele, L'Apis - Dossier.

7. Chen YP, Siede R (2007) Honeybee Viruses. Adv Virus Res 70: 33-80.

8. Bernardini M, Gardi T, Telera G (2001) Effectiveness of Api Life Var and oxalic acid in the fight against varroasis. apitalia 9: 31-34.

9. Gardi T, Giorgetti AC (2014) Biodiversity. An agriculture for the bee, API \& Research, Agricultural World, Apimondia Italy 1(2): 8-32.

10. Gardi T, Ciscato M (2014) Innovative biotechnics: use of hyperthermia in the fight against Varroa destructor (Anderson \& Trueman). Master's thesis. 
11. AAVV (2015) BeeNet project and new honey bee adversity emergency, Umbria Region, Umbria Regional Resources Department, Federalism, Financial, human and instrumental resources, Perugia Chamber of Commerce Headquarters (Via Cacciatori delle Alpi 42), Multipurpose Room.

12. Accorti M, Lutu F, Tarducci F (1991) Methods for collecting data on natural mortality in bee. Ethology, Ecology and Evolution 1: 123-126.

13. Adamik K, FE Braun (1957) Ailanthus altissima as pulpwood. TAPPI 40: 522-526.

14. Feret PP (1985) Ailanthus: Variation, cultivation, and frustration. J Arboric 11(12): 361-368.

15. Gardi T, Ruspolini V (2016) Sistema Alveare e Varroa destructor (Anderson \& Trueman): la termoterapia quale innovativo metodo di lotta.
16. Harlow WH, ES Harrar, JW Hardin, FM White (1996) Textbook of Dendrology ( $8^{\text {th }}$ edn.). Mc Graw-Hill, pp. 459-460.

17. Heisey RM (1996) Identification of an allelopathic compound from Ailanthus altissima (Simaroubaceae) and characterization of its herbicidal activity. Am J Bot 83(2): 192-200.

18. Hoshovsky MC (1995) Ailanthus altissima: Element Stewardship. Abstract.

19. Hu S (1979) Ailanthus. Arnoldia 39(2): 29-50.

20. Lawrence JG, A Colwell, OJ Sexton (1991) The ecological impact of allelopathy in Ailanthus altissima (Simaroubaceae). Am J Bot 78(7): 948958.

21. Miller JH (1990) Ailanthus altissima. In Burns RM, BH Honkala (Eds.), Silvics of North America, pp. 101-105.

22. Stipes RJ (1995) A tree grows in Virginia. Va J Sci 46: 105. 